\title{
Using gridded rainfall products in simulating streamflow in a tropical catchment - A case study of the Srepok River Catchment, Vietnam
}

\author{
Vu Thi Thom ${ }^{1}$, Dao Nguyen Khoi ${ }^{2,3,4 *}$, Do Quang $\operatorname{Linh}^{1}$ \\ ${ }^{1}$ Centre of Water Management and Climate Change, Vietnam National University - Ho Chi Minh City, Ho Chi Minh City, Vietnam. \\ ${ }^{2}$ Environmental Engineering and Management Research Group, Ton Duc Thang University, 19 Nguyen Huu Tho Street, Distric 7, Ho Chi \\ Minh City, Vietnam. \\ ${ }^{3}$ Faculty of Environment and Labour Safety, Ton Duc Thang University, 19 Nguyen Huu Tho Street, District 7, Ho Chi Minh City, \\ Vietnam. \\ ${ }^{4}$ Faculty of Environment, University of Science, Vietnam National University - Ho Chi Minh City, Ho Chi Minh City, Vietnam. \\ *Corresponding author. E-mails: daonguyenkhoi@tdt.edu.vn; dnkhoi86@gmail.com
}

\begin{abstract}
The precise rainfall estimate with appropriate spatial and temporal resolutions is a key input to distributed hydrological models. However, networks of rain gauges are often sparsely distributed in developing countries. To overcome such limitations, this study used some of the existing gridded rainfall products to simulate streamflow. Four gridded rainfall products, including APHRODITE, CFSR, PERSIANN, and TRMM, were used as input to the SWAT distributed hydrological model in order to simulate streamflow over the Srepok River Catchment in Vietnam. Besides that, the available rain gauges data were also used for comparison. Amongst the four different datasets, the TRMM and APHRODITE data show their best match to rain gauges data in simulating the daily and monthly streamflow with satisfactory precision in the 2000-2006 period. The result indicates that the TRMM and APHRODITE data have potential applications in driving hydrological model and water resources management in data-scarce and ungauged areas in Vietnam.
\end{abstract}

Keywords: APHRODITE; CFSR; PERSIANN; TRMM; Rainfall; Streamflow; SWAT model.

\section{INTRODUCTION}

Distributed hydrological models have become useful tools to understand hydrological processes and to solve water resource management problems (Meng et al., 2014). In recent years, many such hydrological models have been developed, such as Agricultural Non-Point Source Pollution (AGNPS) (Young et al., 1989), Hydrologic Simulation Program - Fortran (HSPF) (Donigian et al., 1995), MIKE SHE (Refsgaard and Storm, 1995), and Soil and Water Assessment Tool (SWAT) (Arnold et al., 1998). Amongst these models, SWAT is one of the choices because it is widely used to assess hydrology in small and large catchments around the world (see SWAT Literature database: https://www.card.iastate.edu/swat_articles/index.aspx). However, the distributed hydrological models require a sustainable amount of rainfall data as a key input. In developing countries in the tropical region, networks of ground-based rainfall observations are often sparsely distributed due to economic, technological or terrain limitations, and the situation is unlikely to improve in the near future (Hughes, 2006). Currently, many gridded rainfall datasets have developed for global and regional domains to overcome these shortcomings. Some of these widely datasets, such as the Asian Precipitation Highly Resolved Observational Data Integration Towards Evaluation of Water Resources (APHRODITE) dataset, Climate Forecast System Reanalysis (CFSR) dataset, Precipitation Estimation from Remotely Sensed Information Using Artificial Neural Networks (PERSIANN) dataset, and Tropical Rainfall Measuring Mission (TRMM) product, provide data with high temporal (near real time) and spatial (up to $0.25^{\circ}$ ) resolutions. These datasets will be useful for hydrological studies and water resources management, and provide potential alternative data sources for data-sparse and ungauged regions.

In recent years, evaluation of the performance of gridded rainfall datasets in hydrological modelling over the tropical region has gained considerable attention through numerous studies in many river basins. The results of these studies indicate that the quality of gridded rainfall datasets varies with different topography and regions (Lauri et al., 2014; Worqlul et al., 2014). For example, TRMM products show their best match to rain gauges data over the Nzoia River Basin in Kenya (Ouma et al., 2012), over the Mekong River Basin (Lauri et al., 2014), and over Malaysia (Tan et al., 2015). However, a study in the Dak Bla River Catchment (Vietnam) conducted by $\mathrm{Vu}$ et al. (2012) presented that PERSIANN and TRMM datasets did not show good performance in simulating streamflow compared to observed data. In addition, the similar studies conducted by Dile and Srinivasan (2014) and Casse and Gosset (2015) presented that the CFSR and PERSIANN data proved to be valuable options for hydrological predictions in Blue Nile River Basin and Niger basin, respectively.

Vietnam is a typical tropical country with a mean annual precipitation ranging from 1,200 to $3,000 \mathrm{~mm}$. The country relies on agricultural activities and is subject to frequent floods. Thus, the country critically needs a reliable network of rain gauges. However, the present density of rain gauges in Vietnam is quite sparse (about $400 \mathrm{~km}^{2}$ per gauge), especially in the mountainous and sparsely populated areas. According to the criteria recommended by the World Meteorological Organization (WMO, 1994), the ideal density of rain gauges for tropical zones is 100 to $250 \mathrm{~km}^{2}$ per gauge for mountainous regions and 600 to $900 \mathrm{~km}^{2}$ per gauge for flat regions. Validation of gridded rainfall datasets in Vietnam will give insight into how the different gridded rainfall products perform in this region. The objective of this study is to evaluate the performance of four widely gridded rainfall datasets (namely, APHRODITE, CFSR, PERSIANN, and TRMM) for simulating streamflow - a case study of the Srepok River Catchment in Vietnam. 


\section{STUDY AREA}

The Srepok River Catchment, a sub-basin of the Mekong River Basin, is located in the Central Highlands of Vietnam, and lies between latitudes $11^{\circ} 45^{\prime}-13^{\circ} 15^{\prime} \mathrm{N}$ and longitudes $107^{\circ} 15^{\prime}-109^{\circ} \mathrm{E}$ (Figure 1). The Srepok River is formed by two main tributaries: the Krong No and Krong Ana rivers. The total area of this basin is approximately $12,000 \mathrm{~km}^{2}$ with the population of 2.5 million (2011). The average altitude of the catchment varies from $100 \mathrm{~m}$ in the northwest to $2,400 \mathrm{~m}$ in the southeast. The climate in this area is very humid $(78-83 \%$ annual average humidity) with annual rainfall varying from $1,700 \mathrm{~mm}$ to $2,300 \mathrm{~mm}$ and features a distinct wet and dry season. The wet season lasts from May to October (with peak floods often in September and October) and accounts for over $75-95 \%$ of the annual precipitation. The mean annual temperature is $23^{\circ} \mathrm{C}$. In this basin, there are two dominant soils: grey soils and red-brown basaltic soils. These soils are highly fertile consistent with agricultural development. Agriculture is the main economic activity in this basin of which coffee and rubber production are predominant.

\section{METHODOLOGY}

\section{SWAT hydrological model}

The SWAT model was developed by the United States Department of Agriculture (USDA) Agricultural Research Service (ARS), and designed to predict the effects of land management on the hydrology, sediment and agricultural chemical yields in agricultural watersheds with varying soils, land-use, and management conditions (Arnold et al., 1998). In the SWAT model, a catchment is divided into a number of sub-catchments or subbasins. Sub-basins are further partitioned into hydrological response units (HRUs) based on soil types, land-use, and slope classes that allow a high level of spatial detail simulation. The model predicts the hydrology at each HRU using the water balance equation:

$$
S W_{t}=S W_{0}+\sum_{i=1}^{t}\left(R_{\text {day }}-Q_{\text {surf }}-E_{a}-w_{\text {seep }}-Q_{g w}\right)_{i}
$$

where $S W_{t}$ is the final soil water content (mm), $S W_{0}$ is the initial soil water content (mm), $t$ is the time (days), $R_{d a y}$ is the amount of precipitation on day $i(\mathrm{~mm}), Q_{\text {surf }}$ is the amount of surface runoff on day $i(\mathrm{~mm}), E_{a}$ is the amount of evapotranspiration on day $i(\mathrm{~mm}), w_{\text {seep }}$ is the amount of water entering the vadose zone from the soil profile on day $i(\mathrm{~mm})$, and $Q_{g w}$ is the amount of return flow on day $i(\mathrm{~mm})$.

The SWAT model estimates surface runoff by using the SCS curve number procedure. SWAT calculates the peak runoff rate using a modified rational method. The evapotranspiration is estimated in the SWAT model using the Penman-Monteith method and the channel routing is simulated using the Muskingum method. A detailed description of the water balance components can be found in the SWAT Theoretical Documentation (Neitsch et al., 2011).

The input data required for SWAT include weather data, a land-use map, a soil map, and a Digital Elevation Map (DEM) (Table 1). SWAT requires the weather data at daily time step which can be obtained from a measured dataset or generated by a weather generator algorithm. The required weather data include rainfall, minimum and maximum temperatures, relative humidity, wind speed, and solar radiation. In this study, data taken at six rain gauges and three meteorological station located within and around the basin for 1999-2006, obtained from the Hydro-Meteorological Data Center of Vietnam (HMDC), were used (Figure 1). Discharge data were also required for calibration and validation of streamflow. Daily flow data (2000 to 2006) measured at the Ban Don, Cau 14, Duc Xuyen, and Giang Son stations were used for the calibration and validation of streamflow. Streamflow data were provided by the HydroMeteorological Data Centre of Vietnam. The data in 1999 were

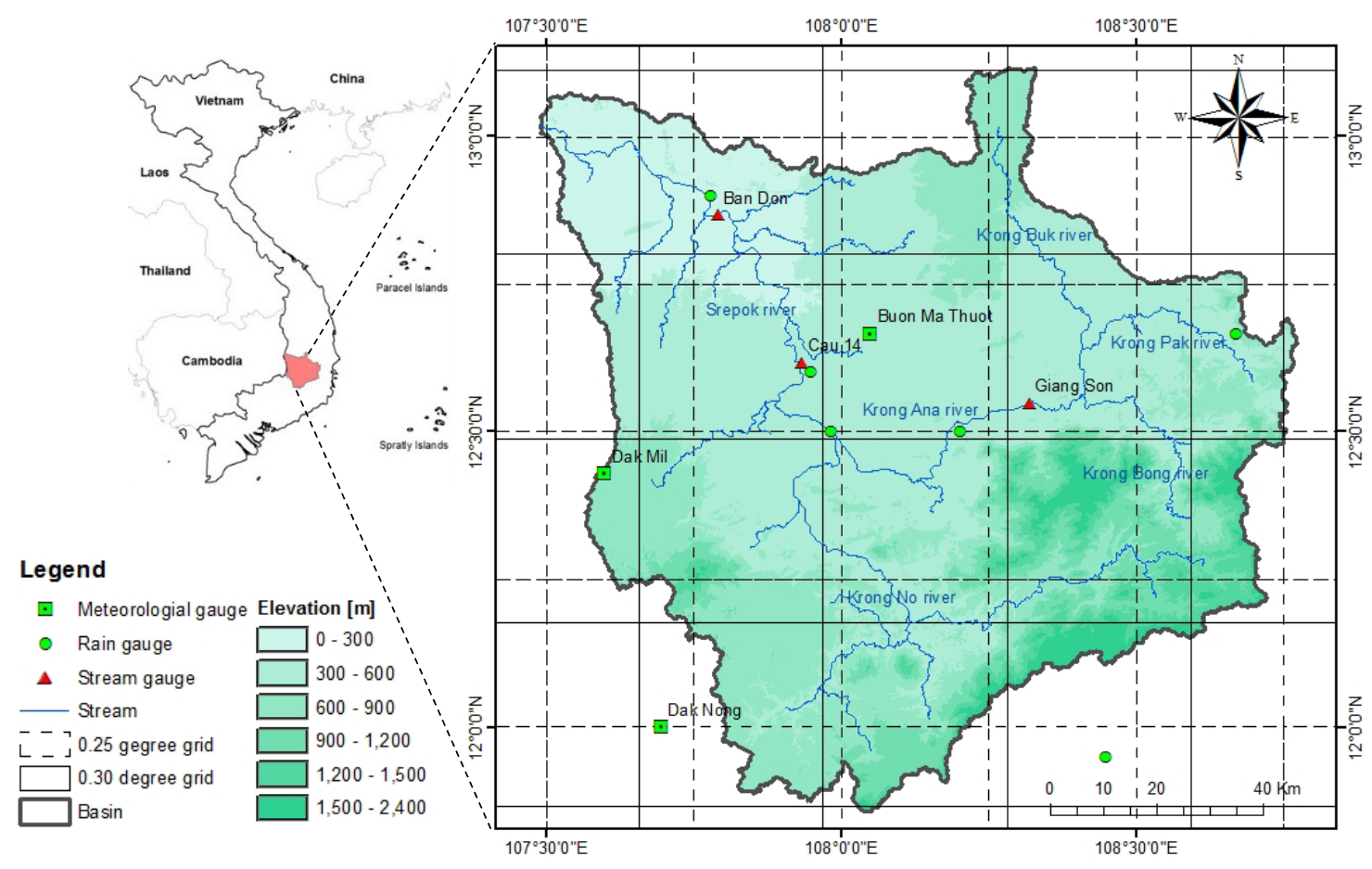

Fig. 1. Location map of the study area. 
Table 1. Data sources used in the initial setup of the SWAT model.

\begin{tabular}{|c|c|c|c|}
\hline Data type & Data description & Scale & Data sources \\
\hline Topography map & Digital Elevation Map (DEM) & $90 \mathrm{~m}$ & USGS-HydroSHEDS \\
\hline Land-use map & Land-use classification in 2003 & $1 \mathrm{~km}$ & Mekong River Commission (MRC) \\
\hline Soil map & Soil types & $10 \mathrm{~km}$ & Food and Agriculture Organization (FAO) \\
\hline Meteorology & $\begin{array}{l}\text { Daily precipitation, minimum and maximum } \\
\text { temperature }\end{array}$ & Daily & $\begin{array}{l}\text { Hydro-Meteorological Data Centre (HMDC); } \\
\text { data for the period 1999-2006 }\end{array}$ \\
\hline
\end{tabular}

Table 2. Description of satellite-based rainfall datasets used in the study.

\begin{tabular}{llllll}
\hline Dataset & Version & Spatial/temporal resolution & Areal coverage & Time coverage & Source \\
\hline APHRODITE & V1101 & $0.25 \%$ daily & Monsoon Asia & $1951-2007$ & Yatagai et al. (2012) \\
CFSR & DS094.1 & $0.30 \%$-hourly & Global & $1979-$ present & Saha et al. (2014) \\
PERSIANN & CDR & $0.25 \%$ daily & Near Global & $1983-$ present & Ashouri et al. (2015) \\
TRMM & 3B42V7 & $0.25 \%$ daily & Near Global & $1998-$ present & Huffman et al. (2007) \\
\hline
\end{tabular}

used as the warm-up period of the simulation. The data from 2000 to 2002 were used for the model calibration, and the data from 2003 to 2006 were used for the model validation. The model set-up consists of four steps: (1) data preparation, (2) sub-basin discretization, (3) HRU definition, (4) calibration and validation. SWAT coupled with ArcGIS as ArcSWAT is used for watershed delineation and other purposes. ArcGIS 10.1 and ArcSWAT 2012 were used in this study. Because the SWAT model is a semi-distributed model, model parameters are varied at different spatial scales (HRUs, sub-basin, and basin) to have different basin characteristics. In order to allow each sub-basin to have its specific basin parameters, the SWAT model was calibrated at gauging stations at the same time to produce one set of optimal parameter values for the whole basin. The model calibration and validation were performed using the SUFI-2 algorithm, which was implemented in the SWAT-CUP 2012 (Abbaspour, 2014).

The Nash-Sutcliffe efficiency (NSE), percent bias (PBIAS), and coefficient of determination $\left(\mathrm{R}^{2}\right)$ were used as statistical indices to assess the model performance. PBIAS measures the average tendency of the simulated value to be larger or smaller than their observed counterparts. The PBIAS value should be close to zero. The positive values indicate the model bias towards underestimation (Moriasi et al., 2007). The formula for PBIAS is as follows

$P B I A S=\left[\frac{\sum_{i=1}^{N}\left(O_{i}-P_{i}\right) \times 100}{\sum_{i=1}^{N}\left(O_{i}\right)}\right]$

where $O_{\mathrm{i}}$ is the observed value, $P_{i}$ is the simulated value, and $N$ is the total number of observations. According to Krause et al. (2005), the model performance for flow simulation is satisfactory when the values of NSE and $\mathrm{R}^{2}$ are between 0.36 and 0.75 , and the PBIAS values are less than $25 \%$.

\section{Gridded rainfall datasets}

Four gridded rainfall datasets, including APHRODITE, CFSR, PERSIANN, and TRMM, were evaluated. Table 2 presents briefly description about the gridded rainfall products used in this study and Figure 1 shows the spatial distribution of the rain gauges within and around the study area with $0.25^{\circ}$ grid for the APHRODITE, PERSIANN and TRMM datasets, and $0.3^{\circ}$ grid for the CFSR product.

\section{APHRODITE dataset}

APHRODITE provides daily gridded rainfall data over Asia for the period 1951-2007, which is generated from rain gauges data obtained from the National Hydrological and Meteorological Services (NHMs). The APHRODITE product is being developed through the activities of the APHRODITE's Water Resources project in collaboration with the Research Institute for Humanity and Nature (RIHN) and the Meteorological Research Institute of Japan Meteorological Agency (MRI/JMA) since 2006. APHRODITE version V1101 with spatial resolution of $0.25^{\circ}$ was selected for this study. More information can be found in Yatagai et al. (2012).

\section{CFSR dataset}

The Climate Forecast System Analysis (CFSR) was designed as a global, high resolution, coupled atmosphere-oceanland surface-sea ice system to provide the best estimate of the state of these coupled domains for the period of 1979 to present. The CFSR version DS094.1 was used in this study. The hourly CFSR global atmosphere data have a spatial resolution of approximately $0.3^{\circ}$. More information about this dataset can be found in Saha et al. (2014).

\section{PERSIANN dataset}

PERSIANN applies an artificial neural network model to measure rainfall rate using infrared (IR) brightness temperature data from geostationary satellites and updating its parameter using passive the microwave (PMW) observations from lowEarth-orbit (LEO) satellites (Ashouri et al., 2015). PERSIANN provides daily and $0.25^{\circ}$ rainfall estimates for latitude band $60^{\circ} \mathrm{S}-60^{\circ} \mathrm{N}$ for the period of 1983 to date. More information about this dataset can be found in Ashouri et al. (2015).

\section{TRMM dataset}

TRMM is a joint mission between the National Aeronautics and Space Administration (NASA) and the Japan Aerospace Exploration Agency (JAXA) to monitor tropical and subtropical precipitation. The daily product TRMM 3B42V7 was used in this study. The version 3B42V7 has a daily temporal resolution and $0.25^{\circ}$ by $0.25^{\circ}$ spatial resolution. The spatial coverage extends from $50^{\circ} \mathrm{S}$ to $50^{\circ} \mathrm{N}$ and $0^{\circ}$ to $360^{\circ} \mathrm{E}$. More information about this dataset can be found in Huffman et al. (2007). 


\section{Approach for evaluating the performance of gridded rainfall products in simulating streamflow}

There are two approaches in evaluating the performance of the gridded rainfall datasets in simulating streamflow (Zeweldi et al., 2011). First approach is calibration of hydrological model using rain gauges data and second approach is calibration of hydrological model using gridded rainfall datasets. Next steps are simulation of streamflow from the well-calibrated hydrological model using rain gauges data and gridded rainfall datasets as inputs and comparison of the simulations with observed streamflow. Among the two approaches, Artan et al. (2007) and Zeweldi et al. (2011) indicated that performance of a hydrological model when the model was calibrated using gridded rainfall data is better than this when it was calibrated using rain gauges data. However, calibration could result in parameter values that are unrealistic as the model attempt to compensate for the large errors in rainfall input (Habib et al., 2014). Thus, the first approach was used in this study.

\section{RESULTS AND DISCUSSION}

\section{Comparison of areal rainfall datasets}

We first evaluated the performance of gridded rainfall datasets against the rain gauges data. For the purpose of hydrological applications, areal comparison of rainfall derived from different datasets is more meaningful (Meng et al., 2014). The areal observed rainfall is then compared with the areal rainfall datasets for the Srepok River Catchment over the 2000-2006 period. The areal rainfall is calculated using Thiessen polygon method by using ArcGIS geoprocessing tool. Figure 2 shows accumulated rainfall curves for rain gauges data and the four gridded rainfall datasets in the 2000-2006 period. The longterm monthly areal rainfall from the five rainfall datasets for the Srepok River Catchment, including averaged rainfall, wet-spell length, and dry-spell length, are presented in Figure 3. The figures show that APHRODITE and TRMM estimates are close to those from the rain gauges data. This is confirmed by the statistical values (including mean, standard deviation, and maximum rainfall) shown in Table 3 . In addition, the coefficient of determination $\left(\mathrm{R}^{2}\right)$ and percent bias (PBIAS) of the four gridded rainfall data against rain gauges data during the period of analysis at daily and monthly scales are shown in Table 4 . It can be seen that the TRMM data have a quite similar trend as the rain gauges data, as shown by the $\mathrm{R}^{2}$ values of 0.23 for daily rainfall and 0.90 for the monthly rainfall, and PBIAS value of $-7 \%$. Besides that, the APHRODITE and CFSR data has also captured the rain gauges data for the study area satisfactory. However, the fit between PERSIANN and rain gauges data are poor. Generally, the APHRODITE and TRMM data showed good performance in capturing the rainfall pattern of rain gauges data in the 2000-2006 period. Our finding is similar to the finding of Tan et al. (2015), who evaluated six gridded rainfall products over Malaysia. In that study, it is indicated that the TRMM and APHRODITE data are reliable and suitable for rainfall estimations in Malaysia.

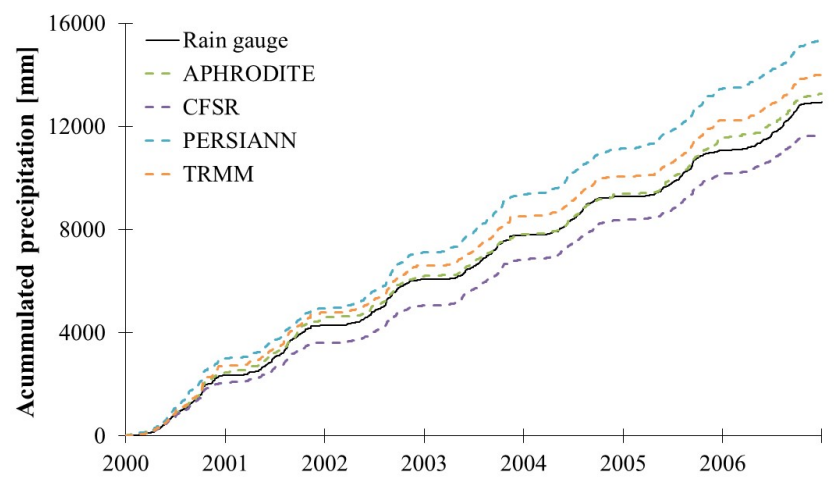

Fig. 2. Accumulated daily precipitation over the Srepok River Basin for rain gauges and gridded rainfall datasets in the 20002006 period.
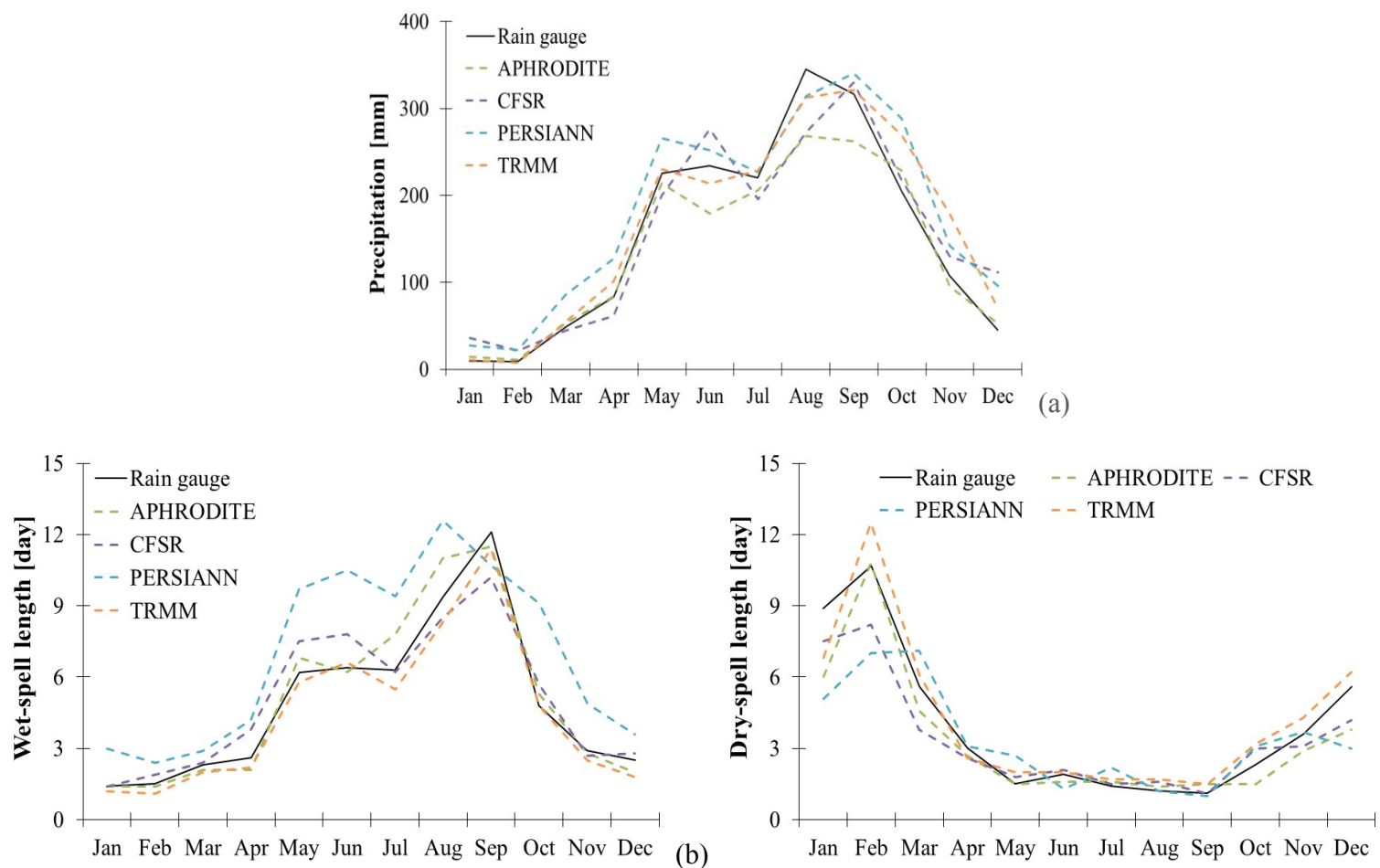

(c)

Fig. 3. Long-term monthly areal rainfall of rain gauges and gridded rainfall products in the 2000-2006 period; (a) averaged rainfall, (b) mean wet-spell length, and (c) mean dry-spell length. 
Table 3. Statistical values of areal averaged rainfall of rain gauges data and four gridded datasets in the 2000-2006 period.

\begin{tabular}{|c|c|c|c|c|c|c|}
\hline & \multicolumn{3}{|c|}{ Daily } & \multicolumn{3}{|c|}{ Monthly } \\
\hline & $\begin{array}{l}\text { Mean } \\
(\mathrm{mm})\end{array}$ & $\begin{array}{c}\text { Standard deviation } \\
\left(\mathrm{mm}^{2}\right)\end{array}$ & $\begin{array}{l}\text { Max rainfall } \\
(\mathrm{mm})\end{array}$ & $\begin{array}{l}\text { Mean } \\
(\mathrm{mm})\end{array}$ & $\begin{array}{l}\text { STD } \\
\left(\mathrm{mm}^{2}\right)\end{array}$ & $\begin{array}{l}\text { Max rainfall } \\
(\mathrm{mm})\end{array}$ \\
\hline Rain gauge & 5.1 & 8.5 & 145 & 154 & 128 & 514 \\
\hline APHRODITE & 5.2 & 8.8 & 122 & 158 & 124 & 598 \\
\hline CFSR & 4.6 & 7.3 & 116 & 139 & 108 & 414 \\
\hline PERSIANN & 6.0 & 9.7 & 104 & 182 & 127 & 535 \\
\hline TRMM & 5.5 & 8.6 & 154 & 166 & 128 & 512 \\
\hline
\end{tabular}

Table 4. $\mathrm{R}^{2}$ and PBIAS between the areal averaged rainfall of rain gauges data and areal averaged rainfall from four gridded rainfall products in the 2000-2006 period.

\begin{tabular}{|c|c|c|c|c|}
\hline & \multicolumn{2}{|c|}{ Daily } & \multicolumn{2}{|c|}{ Monthly } \\
\hline & $\mathrm{R}^{2}$ & PBIAS & $\mathrm{R}^{2}$ & PBIAS \\
\hline APHRODITE & 0.17 & $-4 \%$ & 0.75 & $-4 \%$ \\
\hline CFSR & 0.18 & $10 \%$ & 0.81 & $10 \%$ \\
\hline PERSIANN & 0.13 & $-18 \%$ & 0.67 & $-18 \%$ \\
\hline TRMM & 0.23 & $-7 \%$ & 0.90 & $-7 \%$ \\
\hline
\end{tabular}

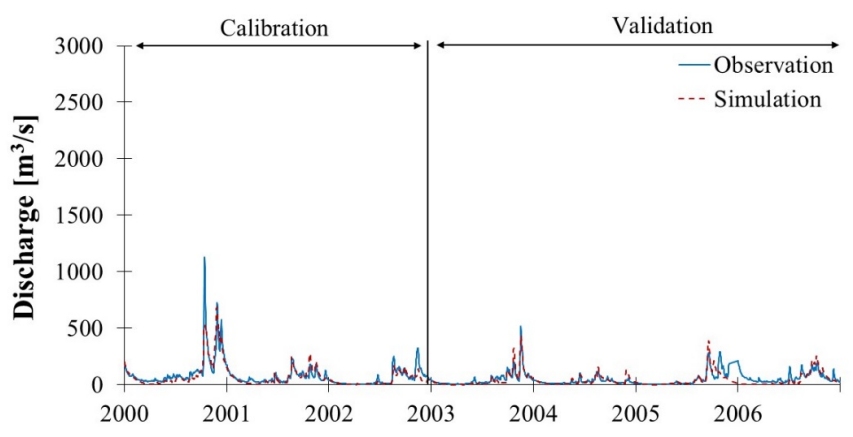

(a) Giang Son station

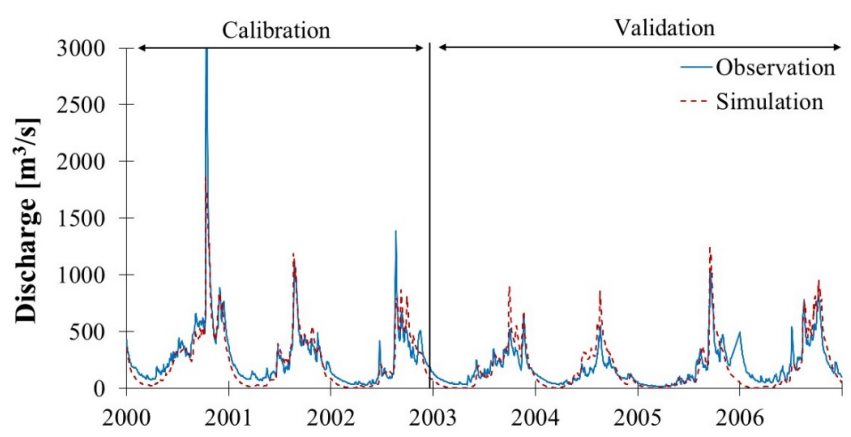

(b) Cau 14 station

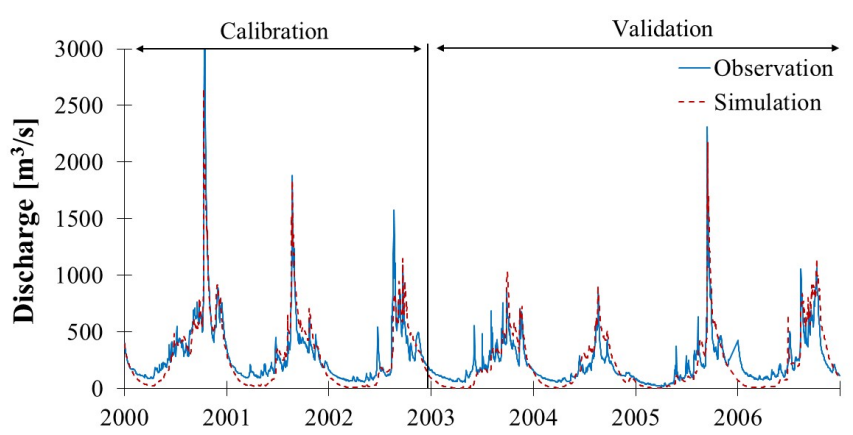

(c) Ban Don station

\section{SWAT calibration and validation}

The SWAT hydrological parameters used for calibration and validation of the model were selected by referring the relevant study in the Be River Catchment (Khoi and Suetsugi, 2012). The selected parameters for the flow simulation were CN2, ESCO, GWQMN, ALPHA_BF, CH_K2. Those parameters are the most sensitive parameters for flow simulation. The calibration and validation of the SWAT model for the Srepok River Catchment were carried out by comparing the simulated streamflow with the observed flow at main gauging stations (the Giang Son, Cau 14, and Ban Don stations). The plots of observed and simulated daily flow are presented in Figure 4. These show that the model produced a similar trend between observed and simulated streamflow during the calibration and validation periods. Although the similar trend was achieved, the peak streamflow was not well matched. This may have resulted from uneven representation of the spatial distribution of rainfall. The statistical indicators for evaluation of the model performance computed using daily streamflow in the calibration and validation periods are listed in Table 5. The observed and simulated daily streamflow showed a good agreement with the NSE, PBIAS and $\mathrm{R}^{2}$ values varying in the range of 0.78 to 0.83 , 8 to $13 \%$, and 0.79 to 0.84 , respectively, for the calibration period. For the validation period, the NSE, PBIAS, and $\mathrm{R}^{2}$ values varied from 0.61 to $0.68,-2$ to $14 \%$, and 0.69 to 0.81 , respectively. Using aggregated monthly average streamflow based on daily streamflow values improved the fit between simulated and observed values. The fit was indicated by the values of NSE, PBIAS, and $\mathrm{R}^{2}$ as shown in Table 5. According to the criteria suggested by Krause et al. (2005), the performance of the SWAT model was considered as "satisfactory" during the calibration and validation periods. The calibrated parameters shown in Table 6 were accepted for the scenario simulations. In the study of Khoi and Thom (2015) over the Srepok River Basin, the SWAT model for flow simulation was calibrated using ten parameters suggested by Khoi and Suetsugi (2012). The SWAT model performance was small difference between the two studies.

Fig. 4. Observed and simulated daily flow hydrograph during the calibration and validation periods. 
Table 5. Model performance for the simulation of streamflow.

\begin{tabular}{|c|c|c|c|c|c|c|c|}
\hline & & \multicolumn{3}{|c|}{ Calibration (2000-2002) } & \multicolumn{3}{|c|}{ Validation (2003-2006) } \\
\hline & & NSE & PBIAS & $\mathrm{R}^{2}$ & NSE & PBIAS & $\mathrm{R}^{2}$ \\
\hline \multirow[t]{2}{*}{ Giang Son } & Daily & 0.78 & $13 \%$ & 0.79 & 0.61 & $14 \%$ & 0.69 \\
\hline & Monthly & 0.87 & $13 \%$ & 0.89 & 0.82 & $14 \%$ & 0.78 \\
\hline \multirow[t]{2}{*}{ Cau 14} & Daily & 0.81 & $13 \%$ & 0.82 & 0.62 & $-2 \%$ & 0.80 \\
\hline & Monthly & 0.89 & $13 \%$ & 0.92 & 0.80 & $-2 \%$ & 0.85 \\
\hline \multirow[t]{2}{*}{ Ban Don } & Daily & 0.83 & $8 \%$ & 0.84 & 0.68 & $1 \%$ & 0.81 \\
\hline & Monthly & 0.89 & $8 \%$ & 0.91 & 0.80 & $1 \%$ & 0.88 \\
\hline
\end{tabular}

Table 6. SWAT calibrated values for flow simulation.

\begin{tabular}{lllc}
\hline Parameter & Description of parameter & Range & Calibrated value \\
\hline V__ALPHA_BF & Baseflow alpha factor & $0 \sim 1$ & 0.30 \\
A_CH_K2 & Channel effective hydraulic conductivity & $-0.01 \sim 500$ & 450 \\
R_CN2 & Initial SCS CN II value & $-0.25 \sim 0.25$ & 0.21 \\
V_ESCO & Soil evaporation compensation factor & $0 \sim 1$ & 0.27 \\
V__GWQMN & Threshold water depth in the shallow aquifer for flow & $0 \sim 5000$ & 1200 \\
\hline
\end{tabular}

A _ parameter value is added by given values

$\mathrm{V}$ - parameter value is replaced by given value

$\mathrm{R}$ _ parameter value is multiplied by $(1+$ a given value $)$

Table 7. Statistical indices for simulating streamflow in the Srepok River Catchment using SWAT in the period 2000-2006.

\begin{tabular}{|c|c|c|c|c|c|c|c|c|c|c|}
\hline \multirow{2}{*}{ Dataset } & \multirow{2}{*}{ Time step } & \multicolumn{3}{|c|}{ Ban Don station } & \multicolumn{3}{|c|}{ Cau 14 station } & \multicolumn{3}{|c|}{ Giang Son station } \\
\hline & & NSE & PBIAS & $\mathrm{R}^{2}$ & NSE & PBIAS & $\mathrm{R}^{2}$ & NSE & PBIAS & $\mathrm{R}^{2}$ \\
\hline \multirow{2}{*}{ Rain gauge } & Daily & 0.79 & $5 \%$ & 0.82 & 0.77 & $6 \%$ & 0.79 & 0.75 & $14 \%$ & 0.77 \\
\hline & Monthly & 0.84 & $5 \%$ & 0.89 & 0.84 & $6 \%$ & 0.87 & 0.84 & $14 \%$ & 0.86 \\
\hline \multirow{2}{*}{ APHRODITE } & Daily & 0.50 & $-8 \%$ & 0.50 & 0.53 & $-13 \%$ & 0.50 & 0.34 & $-45 \%$ & 0.44 \\
\hline & Monthly & 0.62 & $-8 \%$ & 0.68 & 0.64 & $-13 \%$ & 0.66 & 0.39 & $-45 \%$ & 0.59 \\
\hline \multirow{2}{*}{ CFSR } & Daily & 0.42 & $20 \%$ & 0.60 & 0.41 & $32 \%$ & 0.62 & 0.24 & $50 \%$ & 0.31 \\
\hline & Monthly & 0.55 & $20 \%$ & 0.79 & 0.51 & $32 \%$ & 0.80 & 0.25 & $50 \%$ & 0.51 \\
\hline \multirow{2}{*}{ PERSIANN } & Daily & -0.08 & $-45 \%$ & 0.57 & 0.19 & $-40 \%$ & 0.58 & 0.25 & $-29 \%$ & 0.49 \\
\hline & Monthly & -0.11 & $-45 \%$ & 0.76 & 0.21 & $-40 \%$ & 0.76 & 0.31 & $-29 \%$ & 0.64 \\
\hline \multirow{2}{*}{ TRMM } & Daily & 0.56 & $-8 \%$ & 0.60 & 0.59 & $-13 \%$ & 0.60 & 0.42 & $-23 \%$ & 0.42 \\
\hline & Monthly & 0.70 & $-8 \%$ & 0.77 & 0.72 & $-13 \%$ & 0.56 & 0.55 & $-23 \%$ & 0.67 \\
\hline
\end{tabular}

\section{Evaluation of gridded rainfall products using the well-calibrated SWAT model}

To evaluate the streamflow predictions using the different rainfall datasets, experiments based on the well-calibrated SWAT model were conducted with input from rain gauges data and the four gridded rainfall datasets over the study area. These results are shown in daily and monthly scales from daily simulation for the 2000-2006 period. The statistical indices (NSE, PBIAS, and $\mathrm{R}^{2}$ ) are presented in Table 7. Figures 5 and 6 show the comparison of the observed and simulated discharge hydrographs at the daily and monthly scales by different rainfall products.

The results show that the TRMM data perform satisfactorily on observed daily streamflow when it has the closest NSE $(0.56,0.59$, and 0.42$)$, PBIAS $(-8 \%,-13 \%$, and $-23 \%)$, and $\mathrm{R}^{2}$ $(0.60,0.60$, and 0.42$)$ values when compared to the streamflow simulation using rain gauges data (NSE values were $0.79,0.77$, and 0.75 ; PBIAS values were $5 \%, 6 \%$, and $14 \%$; and $\mathrm{R}^{2}$ values were $0.82,0.79$, and 0.77) for the Ban Don, Cau 14, and Giang Son stations, respectively. The APHRODITE data proved to be the next best dataset that was applied to the streamflow simulation, with NSE values of $0.50,0.53$, and 0.34 , PBIAS values of $-8 \%,-13 \%$, and $-45 \%$, and $\mathrm{R}^{2}$ values of $0.50,0.50$, and 0.44 at the Ban Don, Cau 14, and Giang Son stations, respectively. The simulated streamflow driven by the CFSR dataset also shows reasonable agreement with the observed streamflow according to the criteria of Krause et al. (2005), except for the Giang Son station. This was indicated by the values of NSE, PBIAS, and $\mathrm{R}^{2}$ as shown in Table 6. The PERSIANN rainfall data driven streamflow do not show good agreement compared to the rain gauges data as the NSE index show low values of 0.35 . On a monthly scale (Figure 6), the fit between simulated and observed streamflow was improved. The NSE, PBIAS, and $\mathrm{R}^{2}$ values for monthly streamflow simulation driven by the different datasets are also listed in Table 7. In general, the results show that the TRMM data are the best alternative to rain gauges data as input to hydrological modelling, followed by the APHRODITE and CFSR data. The PERSIANN data has failed to perform on streamflow simulation.

Our result is different to that found by Vu et al. (2012) over the Dak Bla River Catchment (its total area is $2,560 \mathrm{~km}^{2}$ ), where the TRMM data did not show a good match in the streamflow simulation. The reason for such difference could be due to the area of the catchment. Lauri et al. (2014) indicated that the TRMM data might not reproduce well the streamflow for the small catchments. Indeed, the APHRODTE and TRMM data did not perform well in stream simulation for the Giang Son station (Table 7). Another reason is likely to be related to TRMM product (TRMM 3B42V7 used in this study 

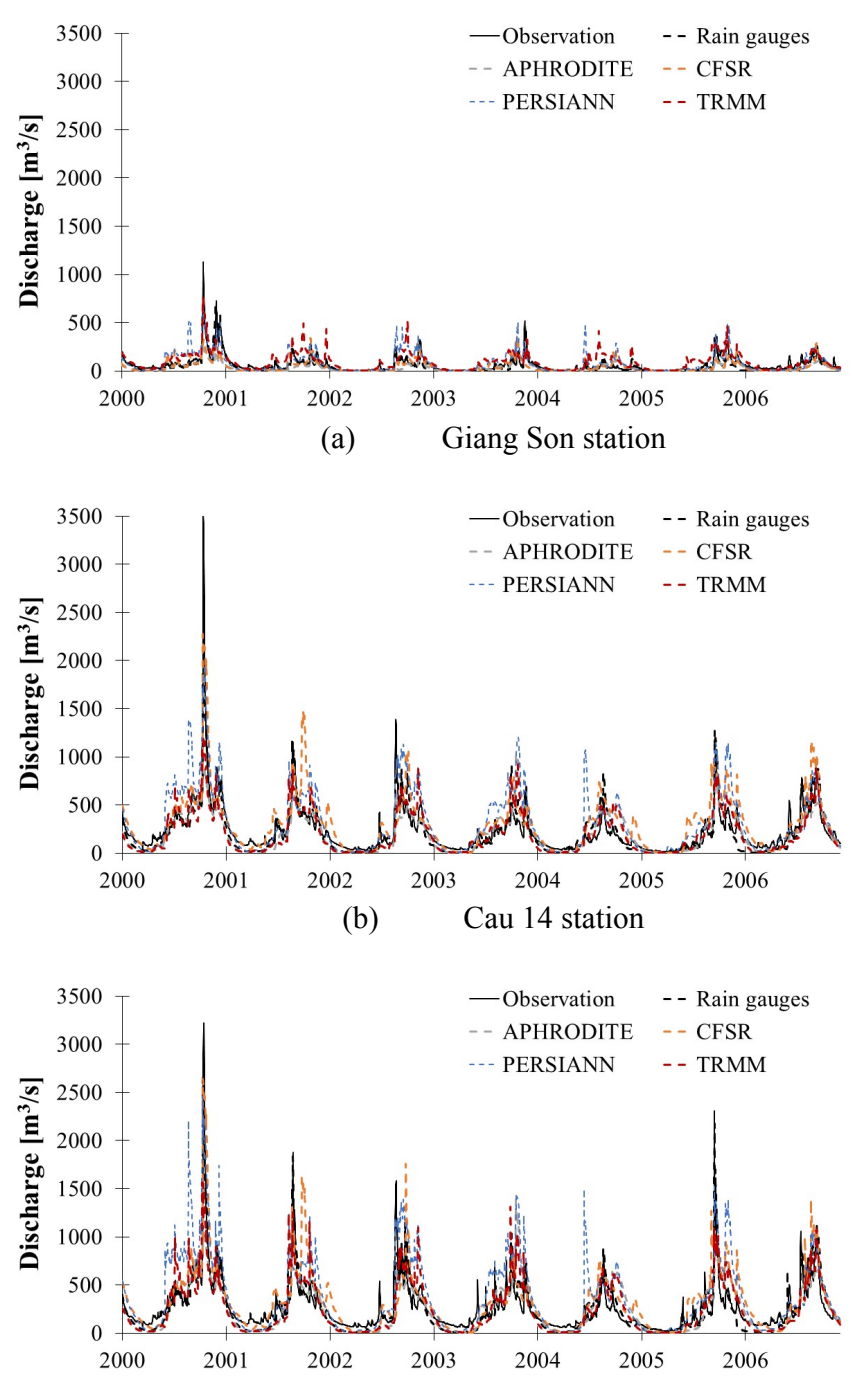

(c) Ban Don station

Fig. 5. Comparison of the daily observed flow and simulated flows from rain gauges and gridded rainfall products.

and TRMM 3B42V6 used in the study by $\mathrm{Vu}$ et al. (2012)). Basically, the difference of the TRMM products comes from algorithm upgrades and addition of new satellite sensors (Milewski et al., 2015). However, our findings agree with the results by $\mathrm{Vu}$ et al. (2012) that the APHRODITE dataset has been performed satisfactorily on hydrological modelling in Vietnam. Besides that, the findings here are similar to that of the study on comparing TRMM and CFSR rainfall data as input for hydrological modelling conducted by Worqlul et al. (2015) in the Upper Blue Nile Basin. He indicated that the CFSR and TRMM data reproduced streamflow reasonably for his study area. Generally, we recommend the use of APHRODITE and TRMM version 7 rainfall data in hydrological studies in Vietnam. However, care should be taken when the APHRODITE and TRMM data are used because of systematic and random errors in TRMM (Muller and Thompson, 2013) and error in temporal-spatial interpolation method of APHRODITE (Ono and Kazama, 2011). Thus, using rain gauges data to correct biases in the gridded rainfall datasets is suggested to reduce those errors before the products can be used in hydrological applications (Muller and Thompson, 2013).
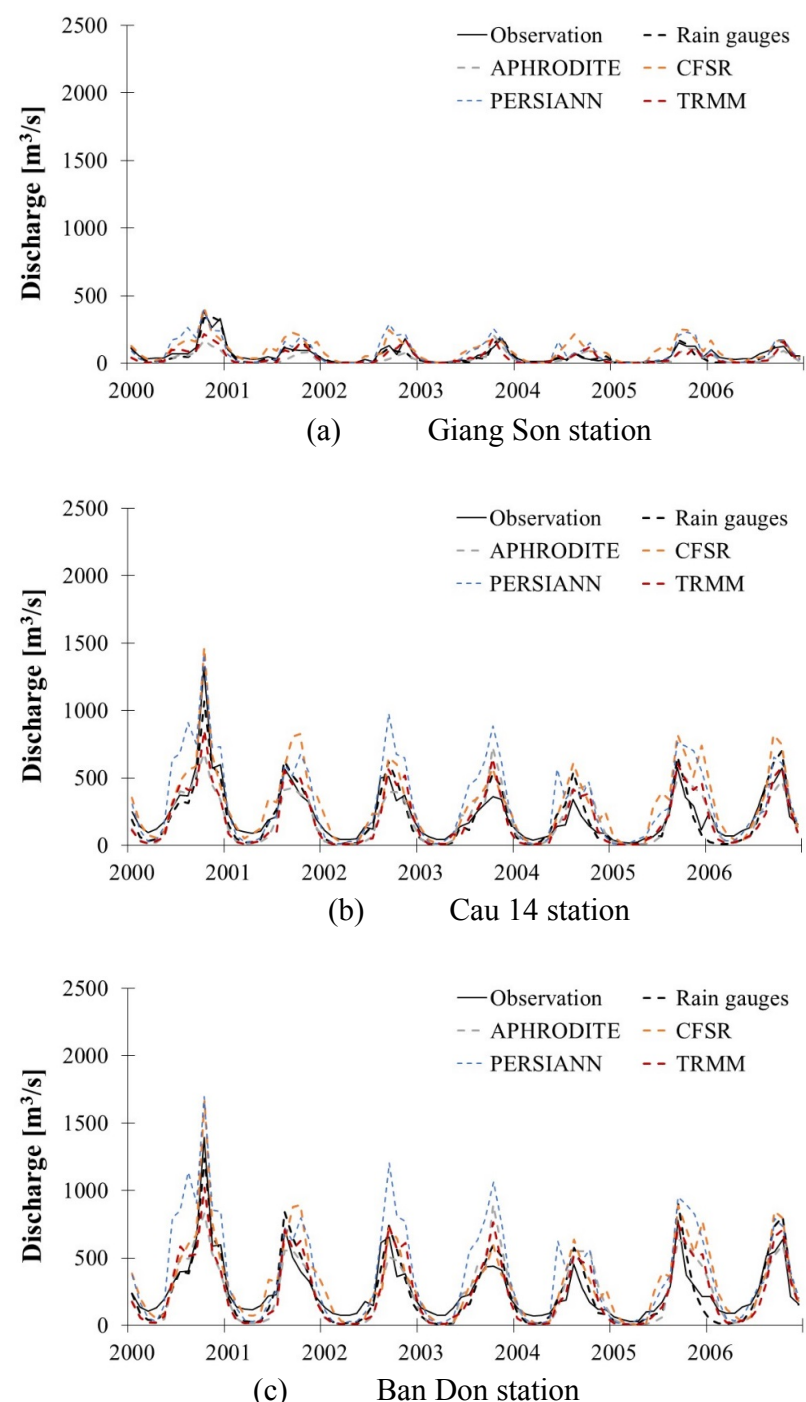

Fig. 6. Comparison of the monthly observed flow and simulated flows from rain gauges and gridded rainfall products.

\section{CONCLUSION}

The main purpose of this study was to assess the utility of gridded rainfall datasets as input into a hydrological model for streamflow simulation in the tropical catchment in Vietnam. The hydrological model used in this study was the SWAT distributed hydrological model and the gridded rainfall datasets included APHRODITE, CFSR, PERSIANN, and TRMM. The streamflow simulation presented that the SWAT model using the rain gauges data produces an overall good fit with observed streamflow, and the TRMM and APHRODITE rainfall data are suited for streamflow simulations in this study area with satisfactory precision. In conclusion, it can be said that the TRMM and APHRODITE data have good potential for useful application to hydrological simulation at daily and monthly time steps, which is a useful merit for regions where networks of groundbased rainfall observations are sparsely distributed.

Acknowledgement. This research is funded by Vietnam National Foundation for Science and Technology Development (NAFOSTED) under grant number “105.06-2013.09”. 


\section{REFERENCES}

Abbaspour, K.C., 2014. SWAT-CUP 2012. SWAT Calibration and Uncertainty Programs - A User Manual. Swiss Federal Institute of Aquatic Science and Technology, Duebendorf.

Arnold, J.G., Srinivasan, P., Muttiah, R.S., Williams, J.R., 1998. Large area hydrologic modelling and assessment, Part I: Model development. Journal of the American Water Resources Association, 34, 73-89.

Artan, G., Gadain, H., Smith, J.L., Asante, K., Bandaragoda, C.J., Verdin, J.P., 2007. Adequacy of satellite derived rainfall data for streamflow modelling. Natural Hazards, 43, 167-185.

Ashouri, H., Hsu, K.L., Sorooshian, S., Braithwaite, D.K., Knapp, K.R., Cecil, L.D., Nelson, B.R., Prat, O.P., 2015. PERSIANN-CDR: Daily precipitation data record from multisatellite observations for hydrological and climate studies. Bulletin of the American Meteorological Society, 96, 1, 69-83.

Casse, C., Gosset, M., 2015. Analysis of hydrological changes and flood increase in Niamey based on the PERSIANNCDR satellite rainfall estimate and hydrological simulations over the 1983-2013 period. Proceedings of IAHS, 370, 117-123.

Dile, Y.T., Srinivasan, R., 2014. Evaluation of CFSR climate data for hydrologic prediction in data-scarce watersheds: an application in the Blue Nile River Basin. JAWRA Journal of the American Water Resources Association, 50, 5, 1226-1241.

Donigian, A.S., Bicknell, B.R., Imhoff, J.C., 1995. Chapter 12: Hydrological simulation program - Fortran (HSPF). In: Singh V.P. (Ed.): Computer Models of Watershed Hydrology. Water Resources Publication, Littleton, Colorado, USA.

Habib, E., Haile, A.T., Sazib, N., Zhang, Y., Rientjes, T., 2014. Effect of bias correction of satellite-rainfall estimates on runoff simulations at the source of the Upper Blue Nile. Remote Sensing, 6, 6688-6708.

Huffman, G.J., Adler, R.F., Bolvin, D.T., Gu, G., Nelkin, E.J., Bowman, K.P., Hong Yang, Sticker, E.F., Wolff, D.B., 2007. The TRMM multisatellite precipitation analysis: Quasi-global, multiyear, combined-sensor precipitation estimates at fine scale. Journal of Hydrometeorology, 8, 38-55.

Hughes, D.A., 2006. Comparison of satellite rainfall data with observations from gauging station networks. Journal of Hydrology, 327, 399-410.

Khoi, D.N., Suetsugi, T., 2012. Hydrologic response to climate change: a case study for the Be River Catchment, Vietnam. Journal of Water and Climate Change, 3, 3, 207-224.

Khoi, D.N., Thom, V.T., 2015. Parameter uncertainty analysis for simulating streamflow in a river catchment of Vietnam. Global Ecology and Conservation, 4, 538-548.

Krause, P., Boyle, D.P., Base, F., 2005. Comparison of different efficiency criteria for hydrological model assessment. Advances in Geosciences, 5, 89-97.

Lauri, H., Rasanen, T.A., Kummu M., 2014. Using reanalysis and remotely sensed temperature and precipitation data for hydrological modelling in Monsoon Climate: Mekong River case study. Journal of Hydrometeorology, 15, 1532-1545.

Meng, J., Li, L., Hao, Z., Wang, J., Shao, Q., 2014. Suitability of TRMM satellite rainfall in driving a distributed hydrological model in the source region of Yellow River. Journal of Hydrology, 509, 320-332.

Milewski, A., Elkadiri, R., Durham, M., 2015. Assessment and comparison of TMPA satellite precipitation products in varying climatic and topographic regimes in Morocco. Remote Sensing, 7, 5697-5717.
Moriasi, D.N., Arnold, J.G., Van Liew, M.W., Bingner, R.L., Harmel, R.D., Veith, T.L., 2007. Model evaluation guidelines for systematic quantification of accuracy in watershed simulations. Transactions of the ASABE, 50, 3, 885-900.

Muller, M.F., Thompson, S.E., 2013. Bias adjustment of satellite rainfall data through stochastic modelling: Methods development and application to Nepal. Advances in Water Resources, 60, 121-134.

Neitsch, A.L., Arnold, J.G., Kiniry, J.R., Williams, J.R., 2011. Soil and Water Assessment Tool Theoretical Documentation Version 2009. Texas Water Resources Institute Technical Report, Texas A\&M University, Texas.

Ono, K., Kazama, S., 2011. Analysis of extreme daily rainfall in Southeast Asia with a gridded daily rainfall data set. IAHS Publication 344, IAHS Press, Wallingford, pp. 169-175.

Ouma, Y.O., Owiti, T., Kipkorir, E., Kibiiy, J., Tateishi, R., 2012. Multitemporal comparative analysis of TRMM-3B42 satellite-estimated rainfall with surface gauge data at basin scales: daily, decadal and monthly evaluations. International Journal of Remote Sensing, 33, 24, 7662-7684.

Refsgaard, J.C., Storm, B., 1995. Chapter 22: MIKE SHE. computer models of watershed hydrology. In: Singh, V.P. (Ed.): Water Resources Publication, Littleton, Colorado.

Saha, S., Moorthi, S., Wu, X., Wang, J., Nadiga, S., Tripp, P., Behringer, D., Hou, Y.T., Chuang, H.Y., Iredell, M., 2014. The NCEP climate forecast system version 2. Journal of Climate, 24, 2185-2208.

Tan, M.L., Ibrahim, A.L., Duan, Z., Cracknell, A.P., 2015. Evaluation of six high resolution satellite and ground-based precipitation products over Malaysia. Remote Sensing, 7, 1504-1528.

Vu, M.T., Raghavan, S.V., Liong, S.Y., 2012. SWAT use of gridded observations for simulating runoff - A Vietnam river basin study. Hydrology and Earth System Sciences, 16, 2801-2811.

WMO (World Meteorological Organization), 1994. Guide to Hydrological Practices: Data Acquisition and Processing, Analysis, Forecasting and other Applications. WMONo.168, WMO, Geneva.

Worqlul, A.W., Maahuis, B., Adem, A.A., Demissie, S.S., Langan, S., Steenhuis, T.S., 2014. Comparison of rainfall estimations by TRMM 3B42, MPEG, and CFSR with groundobserved data for the Lake Tana basin in Ethiopia. Hydrology and Earth System Sciences, 18, 4871-4881.

Worqlul, A.W., Collick, A.S., Tilahun, S.A., Langan, S., Rientjes, T.H.M., Steenhuis, T.S., 2015. Comparing TRMM 3B42, CFSR and ground-based rainfall estimates as input for hydrological models, in data scarce regions: the Upper Blue Nile Basin, Ethiopia. Hydrology and Earth System Sciences Discussions, 12, 2081-2112.

Yatagai, A., Kamiguchi, K., Arakawa, O., Hamada, A., Yasutomi, N., Kitoh, A., 2012. APHRODITE: Contructing a long-term daily gridded precipitation dataset for Asia based on a dense network of rain gauges. Bulletin of the American Meteorological Society, 93, 1401-1415.

Young, R.A., Onstad, C.A., Bosch, D.D., 1989. AGNPS: a nonpoint source pollution model for evaluating agricultural watersheds. Journal of Soil and Water Conservation, 44, 2, 168-173.

Zeweldi, D.A., Gebremichale, M., Downer, C.W., 2011. On CMORPH rainfall for streamflow simulation in a small, Hortonian watershed. Journal of Hydrometeorology, 12, 456-466. 